\title{
The advertising mix for a search good
}

\author{
Simon P. Anderson*and Régis Renault ${ }^{\dagger}$
}

Revision: December 2011

\begin{abstract}
We extend the persuasion game to bring it squarely into the economics of advertising. We model advertising as exciting consumer interest into learning more about the product, and determine a firm's equilibrium choice of advertising content over quality information, price information, and horizontal match information. Equilibrium is unique whenever advertising is necessary. The outcome is a separating equilibrium with quality unravelling. Lower quality firms need to provide more information. For a given quality level, as a function of consumer visit costs, first quality information is disclosed, then price information and then horizontal product information are added to the advertising mix. Some suggestive evidence is provided from airline ads in newspapers.

Keywords: persuasion game, advertising, search, content analysis, information

JEL Classification: D42 L15 M37

Acknowledgement 1 We gratefully acknowledge travel funding from the CNRS and NSF under grants INT-9815703 and GA10273, and research funding under grant SES-0137001. We thank participants at the first Workshop on the Economics of Advertising and Marketing, the Network on Industrial Economics (UK), the CES-Ifo Applied Microeconomics conference, and various seminars, and the Universities of Perpignan and Toulouse (IDEI) and Melbourne Business School for their hospitality. Many thanks to two referees, an Associate Editor and the Editor for constructive and insightful suggestions.
\end{abstract}

\footnotetext{
*Department of Economics, University of Virginia, PO Box 400182, Charlottesville VA 22904-4128, USA. sa9w@virginia.edu

${ }^{\dagger}$ ThEMA, Université de Cergy-Pontoise, 33 Bd. du Port, 95011, Cergy Cedex, FRANCE. regis.renault@eco.ucergy.fr
} 


\section{Introduction}

Product advertising works to raise profits in many different ways (Erdem et al. 2008b). These include informing consumers, price reassurance, quality signaling, getting the product included in the consideration set, etc. ${ }^{1}$ One way advertising works is to attract initial consumer attention to a purchase opportunity. ${ }^{2}$ Once the potential consumer is interested, she will either find out more, at further cost, or buy the product. Once she decides to buy, there is an additional cost above the price paid, which is the cost needed to get to the store (or the relevant web-site) to make the transaction. In this context, advertising can entice the prospective customer to make the further spending of time and money needed to eventually buy the product. This means that the ad must promise enough to make this worthwhile. The promise made can take several forms - it can involve price reassurance, it can bolster perceived quality, or it can appeal to the particular desires of a subset of consumers. All these types of information - prices, quality, idiosyncratic matches - could be in an ad. This paper is about which of these dimensions a firm will stress, and is the first in the literature to take on all these dimensions. Doing so gives strong predictions into advertising content: high quality products may advertise their quality alone, lower quality ones must add price reassurance into the mix, and even lower quality ones must appeal to specific consumer characteristics. Other models in the literature deliver some parts of this picture, although with some drawbacks (as discussed below). Ours takes on all dimensions, with strong predictions for patterns of advertising content.

Many advertisements contain quality information about the product advertised. Quality may be considered a "vertical" characteristic insofar as all consumers agree that a higher quality is better. Ads also frequently contain "horizontal" product information that tells the consumer more about whether her particular tastes and preferences mesh well with those the product provides. They also may or may not deliver price information. ${ }^{3}$

\footnotetext{
${ }^{1}$ Of course, the marketing literature has addressed these various roles in some detail. Informing consumers is considered by Mehta et al. (2008), and Almadoss and He (2009); price reassurance by Iyer et al. (2005), and Erdem et al. (2008); quality signaling by Zhao (2000), and Kalra and Li (2008); Kalra and Li (2008), Mehta et al. (2003), and Yee et al. (2007) look at the firm problem of getting the product included in consideration set.

${ }^{2}$ See Kotler and Armstrong (2009), and Zhang and Krishnamurthi (2004).

3 "Content Analysis" in marketing looks at the information contained in ads. Most of the literature has followed the taxonomy of Resnik and Stern (1977) in categorizing 14 possible "information cues" (such as price, quality, performance, availability) that an ad may contain. Information content is described by the number of information cues the ad claims. Abernethy and Butler (1992) find price information was given for $68 \%$ of newspaper ads; $40 \%$ had 4 or more cues. Abernethy and Franke (1996) present a "Meta-analysis" that compiles the results from previous studies. Only $19 \%$ of magazine ads reported price information (based on 7 studies of US magazines), and the mean number of cues was 1.59 , with only $25.4 \%$ having three or more cues, and $15.6 \%$ having no cues. The mean number of cues in US television advertising (based on 4 previous studies) was 1.06 , with only $27.7 \%$ having two or more cues, and $37.5 \%$ having no cues. Other papers in the content analysis tradition have compared content over time (e.g., Stern and Resnik 1991), and across cultures (e.g., Madden, Caballero, and Matsukubo 1986). Abernethy and Franke (1998) find that content was significantly lower when the FTC campaign against misleading ads was more vigorous.
} 
The firm faces various tensions and trade-offs in choosing its advertising content. First, advertising price may draw in consumers, but at a lower price than could have been charged if price were not advertised (since arriving customers would have already sunk a cost to get as far as the purchase point, and there the firm has a "hold-up" advantage over them). Second, advertising quality may be unattractive to the firm if its quality is mediocre, but, as discussed below, the standard wisdom of the "persuasion game" says it still needs to do so. Third, advertising attributes that have a niche appeal may well bring in some consumers liking that niche, but turns off others with different tastes (see Anand and Shachar 2011 for empirical substantiation).

The paper delivers the solution to these trade-offs. It also contributes by bringing the "persuasion game" squarely into the economics of advertising, both by adding the further dimensions of content that could be revealed, and also allowing for the cost of getting to the purchase point. ${ }^{4}$ In the original persuasion game, a firm must choose what (verifiable) quality attributes to reveal to the consumer. ${ }^{5}$ There is a single consumer type, whose quantity demanded rises with the expected quality level. The price of the good is fixed exogenously. There is no consumer search so that she buys on the grounds of expected quality. The good sold may therefore be thought of as an experience good, though only at a rather superficial level insofar as there is no repeat purchase option. As Milgrom (1981) and Grossman (1981) show, the unique equilibrium is for the firm to reveal all of its quality information. ${ }^{6}$ This is because withholding some quality information would only reduce quantity demanded at the fixed price because the consumer in equilibrium infers that the withheld information is unflattering. ${ }^{7}$ This is an unraveling result insofar as qualities can be thought of as being revealed from the top down. Farrell (1986) puts it as follows: "Suppose that the seller refuses to disclose $q$. What should buyers infer about $q$ ? Clearly, they should not infer that $q$ is at the top of the range - for if they did so, then lower $q$ 's would follow that concealment strategy. But then the buyers' beliefs have to be such that if $q$ were in fact at the top of the range, then the seller would rather reveal $q$. Next we apply the same argument to the range remaining after the top q's drop out...and so on." 8

\footnotetext{
${ }^{4}$ The "persuasion game" needs to be clearly distinguished from what is often (somewhat colloquially) known as persuasive advertising. Such advertising, while commonplace in marketing discussions, often sits uneasily with economists who are disturbed by the idea that tastes might be shifted.

${ }^{5}$ For example, a car manufacturer may state that the car goes from zero to 60 m.p.h. in 5.3 seconds, or it may not report the acceleration information.

${ }^{6}$ Milgrom and Roberts (1986a) elaborate the basic persuasion game of Milgrom (1981), while Matthews and Postlewaite (1985) give an interesting perspective on voluntary disclosure of information when the firm can choose whether or not to engage in research that uncovers the product quality.

${ }^{7}$ Koessler and Renault (2011) provide a necessary and sufficient condition for this unraveling result to hold with a more general demand specification that allows for horizontal match differentiation across consumers.

${ }^{8}$ A subsequent literature (see the surveys by Milgrom 2008, and Dranove and Jin 2010) has explored where there may not be full disclosure (for example, when there are costs to disclosure).
} 
We extend the persuasion game by allowing for search characteristics (as opposed to the experience characteristics treated in the original formulation). Most importantly, price should be viewed as a search characteristic because it is observed before purchase (indeed, the original persuasion game assumes that prices are known.). Notice though that this is interesting only if there are visit costs associated with buying the product because otherwise there would be no cost to finding out the missing information. The problem then facing the firm in this view of advertising is whether to give out information (how much and of what type) before the visit cost is incurred, in order to influence the visit decision. As argued above, much advertising is about getting the consumer into the store in the first place, and incurring the costs of doing so.

Of course, other papers deliver some part of the messages that ours does, and describe advertisements playing some of the roles that ours do. The role of price assurance in ads is delivered by Konishi and Sandfort (2002), for example, but they do not consider quality or horizontal characteristics. The original persuasion game literature delivers the unraveling result - that all firm types reveal their true quality for fear of being taken as the worst possible quality - our analysis indicates that it does not hold for a search good with low search costs. There has been a recent literature on disclosure games. These papers have mainly described the experience good context, so allowing for price advertising is not an option in these models. They are limited in terms of the other dimensions of products that can be revealed, with the exception of Koessler and Renault (2011), who treat the general monopoly case. Three prominent papers are Sun (2010), Guo and Zhao (2009), and Board (2009). Sun deals with both horizontal product information (using the classic linear city model, with a monopolist of unknown location) and a quality dimension: first quality is assumed known, and then it is assumed unknown. In the latter case she assumes that the firm must disclose either all information or none at all, so she does not allow the decisions to be split up. Guo and Zhao (2009) address duopolists' incentives to reveal quality information, under the assumption that each is ignorant of the other's quality; Board (2009) does similarly assuming that they know each other's quality. ${ }^{9}$

Apart from these recent papers on disclosure, the economics literature has scarcely addressed the informational content of ads. ${ }^{10}$ The literature on informative advertising (see for example Butters 1977 for a competitive analysis, and Shapiro 1980 for the monopoly case) has been mostly concerned with advertising "reach," which is the number of consumers that see the ad, and whether this is socially excessive or not. Since the typical assumption is that the product sold is homogeneous, all the ad needs to communicate is the product price and where the consumer can buy it. ${ }^{11}$

\footnotetext{
${ }^{9}$ See also Mazlin and Shin (2010) for a model with two quality attributes and a limited communication technology.

${ }^{10}$ An excellent survey of the Economics of Advertising is Bagwell (2007).

${ }^{11}$ For exceptions to the homogeneity assumption, see Grossman and Shapiro (1984), Meurer and Stahl (1994), and
} 
Information is also conveyed by quality signaling. The signaling explanation for advertising allows for consumers to infer high product quality from seeing copious advertising expenditure, but the ad need convey nothing in terms of hard information about the actual product. Money just needs to be conspicuously "burnt" to communicate the point to the viewer of the ad (see Nelson 1970, 1974, Kihlstrom and Riordan 1984, and Milgrom and Roberts 1986b).

Integrating the persuasion game into advertising theory by treating the product sold as a search good enables us to give richer foundations to the observed patterns of advertising content. Consumer search costs and vertical product quality underpin the comparative statics properties. Our results suggest that ads are most likely to include quality information, with price or horizontal match information depending on how much control the firm has over the type of horizontal match information it can transmit. Also, low quality firms are more likely to advertise additional attributes and price. It is also true in our model that consumers are enticed by the ad to find out more about the product, but some do not eventually buy (see also Bar-Isaac et al. 2010 for a setup where consumers may buy without finding out) - the fraction not buying is larger for lower quality goods when only quality is advertised.

The paper is organized as follows. The model and its development are described in the following sections, first with quality-only advertising and then quality-and-price advertising. This analysis constitutes the basic persuasion game applied to search goods and allowing for price advertising. We then allow in addition for advertising over horizontal characteristics, and we treat two variants. The first is that horizontal product advertising must fully reveal the consumer's valuation for the good and is described in the main text. The second is that the firm has full control over just how much information may be revealed (subject to the constraints of Bayesian updating for the consumer). This will transpire to be threshold match advertising and is treated in the Appendix. The final Section concludes.

\section{The Model}

A monopolist sells a product of intrinsic quality $q \in[\underline{q}, \bar{q}]$. This quality is known to the firm, but not to the consumer. The product is produced at constant marginal cost, normalized to zero and the firm maximizes expected profit.

The consumer incurs a search cost (or visiting cost), $c$, in order to be able to buy from the firm. This cost is incurred whether or not the product is actually bought, but the consumer can avoid it by not visiting (which precludes her from buying). If she visits, she either buys one unit of the

Christou and Vettas (2008). 
product from the firm, at price $p$, or else does not buy. Conditional on incurring the search cost, consumer utility from buying a product of quality $q$ at price $p$ is given by

$$
u=q-p+\varepsilon
$$

We assume that the consumer-specific valuation (henceforth her "match value") $\varepsilon$ is distributed on $[0, b]$ where $b>0$. This implies $\underline{q}>-b$, or else the lowest quality product would never be bought. In this sense, $\underline{q}=-b$ is a natural lower bound to the possible quality. Note that at any positive price, "negative" qualities $-b<q<0$, will only be bought for sufficiently good realizations of $\varepsilon$. However, if $q>0$, the consumer will always buy if the price is low enough. Here consumers are ex-ante identical since they share the same search cost, the same quality valuation, and the same prior about their match (which is also the firm's prior). The number of consumers is normalized to one, where the only source of heterogeneity among consumers is captured by the probability distribution on $[0, b]$ for the match realization.

Let $f$ be the density and $F$ the corresponding cumulative distribution of the match value. We assume further that $1-F$ is strictly log-concave. ${ }^{12}$ All this is common knowledge. It means that, absent any advertising that might inform her otherwise, the consumer's valuation of the product is unknown to her before inspection of the good. One example is the standard uniform distribution with $b=1$ and $f(\varepsilon)=1$ for $\varepsilon \in[0,1]$, which yields a standard linear expected demand curve with price intercept $1+q$.

Once she is at the store, the consumer finds out her match and the price, so she is willing to buy if $q+\varepsilon \geq p$, because she then observes everything. ${ }^{13}$ Her visit decision hinges around whether her expected surplus exceeds the search cost, $c .{ }^{14}$ Because she always has the option of not buying, her expected surplus is the expected maximum of $q+\varepsilon-p$ and 0 .

If advertising features the price, it is assumed to be binding. If the ad does not give the price, the consumer must predict it when deciding if she should visit. Advertising may also provide information on the product quality, $q$. In keeping with the standard persuasion game, we assume that the firm may not over-claim quality. Finally, an ad may tell the consumer her specific value of $\varepsilon$. This is information that the firm may furnish that enables the consumer to determine her match. ${ }^{15}$ Note that the firm does not know the actual $\varepsilon$ value of the consumer. Advertising is assumed to be costless. We do invoke a tie-breaking rule, that any broad type of information, be

\footnotetext{
${ }^{12}$ Equivalently, we suppose that the "hazard rate" $f /(1-F)$ is strictly increasing.

${ }^{13} \mathrm{We}$ assume she buys if she is indifferent between buying and not.

${ }^{14}$ We assume she visits if she is indifferent between visiting and not.

${ }^{15}$ For example, in the context of the circle model of Salop (1979), a firm may communicate its location on the circle.
} 
it price, quality or match, will only be advertised if so doing strictly increases profit. ${ }^{16}$

To sum up, the game has four stages: (i) the firm finds out quality; (ii) the firm selects its price and advertising strategy according to its quality; (iii) the consumer decides whether to visit or not after seeing the information in the ad, if any; (iv) If the consumer visits, she decides whether to buy or not after seeing all remaining information. We are interested in finding the pure strategy perfect Bayesian equilibria when all information types can be advertised. To get there, we build up the analysis by introducing additional options sequentially, in the order in which they will ultimately appear in equilibrium (as a function of increasing visit costs). This is a pedagogical device; we are not attempting to compare all possible combinations of information revelation, just the equilibrium ones. Hence, in the sequel, we first derive conditions under which the market exists even if no advertising is feasible. We then introduce the possibility of quality-only advertising, to which we then add price advertising, and then match advertising. At that juncture we have all the information instruments in play. We then show that the outcome is unique whenever search costs are large enough that no equilibrium could exist without some form of advertising (the interesting case), under the restriction that the distribution of qualities is continuous over a convex support.

\section{No advertising}

If the firm provides no information, the consumer must rationally anticipate the price it will charge and the quality of its product, conditional on observing that the firm does not advertise. She will then visit if her expected surplus exceeds the search cost, $c$. Anderson and Renault (2006) analyze the case where the consumer knows the quality, but they do not draw out the impact of different quality levels.

If there is no advertising and the consumer does not know the quality beforehand, we need to think through what the firm and consumer will do. Notice here that if the consumer were to visit, she would then observe the quality and her match (our search good assumption), and would then buy if her combined valuation exceeds the price. The probability the consumer buys at price $p$ is $1-F(p-q)$.

Define now $p^{m}(q)$ as the monopoly price for a firm with quality $q$, so that the monopoly price $p^{m}$ maximizes expected revenue $p[1-F(p-q)]$. The strict log-concavity assumption ensures the marginal revenue curve to the demand curve slopes down. This implies that the marginal revenue curve either crosses the marginal cost curve (which is zero by assumption here) for an output below one or else marginal revenue is still positive at an output of one. The former case means a price

\footnotetext{
${ }^{16}$ The rule is loosely based on the idea that including more types of information in an ad is more costly.
} 
above $q$ (but below $q+b$, or else no-one would buy) and given by the interior solution to the first-order condition, $p^{m} f\left(p^{m}-q\right)=\left(1-F\left(p^{m}-q\right)\right)$, which we rewrite as

$$
p^{m} \frac{f\left(p^{m}-q\right)}{1-F\left(p^{m}-q\right)}=1
$$

where the strict log-concavity assumption implies that $\frac{f(z)}{1-F(z)}$ is an increasing function of the argument $z=p-q$. An increase in $q$, with $p$ constant, raises the LHS of (1); an increase in $p$ is therefore needed to restore the equality in (1). The other case (when there is no interior solution to the first-order condition) corresponds to a price $p^{m}=q$, and this case arises for all $q$ exceeding a (unique) threshold level denoted $\tilde{q}=1 / f(0)$, which is where the profit derivative is zero with an output of 1 and a price equal to $\tilde{q}$. We then have:

Lemma 1 The monopoly price $p^{m}(q)$ increases in $q$ under the strict log-concavity assumption, with $p^{m}(q)>q$ for $q<\tilde{q}$ and $p^{m}(q)=q$ for $q \geq \tilde{q}$, where $\tilde{q}=1 / f(0)$.

Since we have just shown that $p^{m}(q)$ increases in $q$ when (1) holds, then $p^{m}-q$ must decrease with $q$ for $q<\tilde{q}$, again to retain the equality in (1). This implies that the consumer is better off with higher quality, since the price rise does not fully offset the quality rise. Define the corresponding level of conditional consumer surplus as

$$
S^{m}(q)=E\left(\max \left\{q+\varepsilon-p^{m}, 0\right\}\right)=\int_{p^{m}-q}^{b}\left(q+\varepsilon-p^{m}\right) f(\varepsilon) d \varepsilon,
$$

which is increasing in $q-p^{m}$. Then we have:

Lemma 2 The consumer surplus $S^{m}(q)$ increases in $q<\tilde{q}$ under the strict log-concavity assumption. For $q \geq \tilde{q}$, consumer surplus $S^{m}$ is independent of $q$ : in this case all consumers buy and increases in quality are fully captured in price increases.

Hence, the lowest possible surplus, with consumers rationally anticipating monopoly pricing, avails when the quality is as low as possible, $\underline{q}$. Moreover, the higher the actual quality, the higher the corresponding surplus. Even though the monopoly price rises, it does so at a rate slower than the quality. ${ }^{17}$

If advertising is infeasible, the consumer will be prepared to incur the visit cost (rationally anticipating the monopoly price for whatever quality value she finds) for values of $c$ up to the value $\tilde{c} \equiv E\left(S^{m}(q)\right)$, i.e., the expectation over $q$ of $S^{m}(q)$. In summary:

\footnotetext{
${ }^{17}$ This is similar formally to the property that unit taxes (or indeed, unit cost hikes) are absorbed under monopoly with well-behaved (i.e., log-concave) demand. For more on such properties, see Anderson, de Palma, and Kreider (2001) and Weyl and Fabinger (2009).
} 
Proposition 1 If advertising is not feasible, the market is served if $c \leq \tilde{c}$ and the monopoly price $p^{m}(q)$ is charged corresponding to the actual quality $q$.

As we shall shortly see, this outcome continues to be an equilibrium for low $c$ when qualities can be advertised, but the ability to advertise also generates other equilibria with disclosure.

\section{Quality Advertising}

Suppose now that it is possible to advertise quality, but not price (nor any horizontal match information). The monotonicity property of Lemma 1 will separate out firm types' actions by quality level. We continue to invoke the tie-breaking rule that a firm will not advertise quality when it is indifferent.

Clearly then no firm type advertises for $c \leq S^{m}(\underline{q})$. This is because consumers anticipate a positive surplus even with the lowest quality type at its monopoly price and so will visit the store regardless. For larger search costs, one equilibrium involves all firm types pooling on not revealing quality. This can arise for $c$ between $S^{m}(\underline{q})$ and $\tilde{c}$, so the consumer is still willing to visit while expecting to be charged the monopoly price and having no information on quality. Likewise, the types have no incentive to declare their actual qualities since the consumer always visits. For $c>\tilde{c}$, there is no such full pooling equilibrium because the consumer will not visit without price or product information, and a high quality firm will deviate from an advertising strategy at which quality is not revealed.

For sufficiently large search costs, there is also a separating equilibrium where the firm advertises quality if and only if quality is sufficiently high for it to make strictly positive sales. ${ }^{18}$ Anticipating the pricing outcome, the consumer (after learning that quality is $q$ ) will only visit if the search cost is at most $S^{m}(q)$. The monotonicity property in Lemma 2 implies that only firm types with higher $q$ 's are visited and hence choose to advertise. Define $c_{1 q}=S^{m}(q)$. By Lemma 2, this threshold level is increasing in $q<\tilde{q}$ and is constant for $q \geq \tilde{q}$.

Suppose that the search cost is $c_{1 q}$ for some $q$. Then any firm type with quality strictly below $q$ is stuck with no sales because consumers rationally anticipate a hold-up problem should they visit. This is a variant of the hold-up problem described by Stiglitz (1979) and related to the "Diamond paradox" (Diamond, 1971) . It is only firms with a quality strictly above $q$ which, by advertising information certifying quality, can convince consumers that they will retain positive expected surplus should they visit. Such a separating equilibrium exists if and only if $c>c_{1 \underline{q}}$. High

\footnotetext{
${ }^{18}$ We refer to this equilibrium as separating because the active firm types separate, modulo the caveat that inactive types pool on not advertising.
} 
quality firms are induced to advertise quality because otherwise, consumers update their beliefs in a Bayesian manner, and assign a probability of 1 to a $q$ value such that $c_{1 q}<c$, so that they do not visit. To see that there cannot be any other equilibrium, note that it is not possible that some but not all firm types such that $c_{1 q}>c$, pool with the low quality types by not advertising. This would require that they obtain their monopoly profit, but then, from the tie breaking rule, all high quality firms should choose to not advertise. This leads to the following result.

Proposition 2 If only quality advertising is feasible, then for any search cost there are at most two equilibria. For $c \in[0, \tilde{c}]$ there is a pooling equilibrium at which the firm does not advertise, as per Proposition 1. Second, for $c \geq c_{1 \underline{q}}$ there is a separating equilibrium at which a firm with quality $q$ advertises its quality for $c \in\left(c_{1 \underline{q}}, c_{1 q}\right]$. It charges its monopoly price $p^{m}(q)$ and consumers rationally anticipate this and visit. A firm with quality $q$ cannot sell if $c>c_{1 q}$. The critical value of search cost, $c_{1 q}$, is increasing in $q<\tilde{q}$, while $c_{1 q}=c_{1 \tilde{q}}$ for $q \geq \tilde{q}$.

It is important for what follows to note that if $c \in\left(c_{1 \underline{q}}, c_{1 q}\right]$, there is no benefit to the firm of type $q$ from advertising any additional information since it already attains the monopoly price and profit. If a firm has quality $q$, and $c>c_{1 q}$, it must add to the advertising mix because consumers need further inducement to incur the search cost.

From Proposition 2, for $c>\tilde{c}$, there is only the separating equilibrium where only firm types with a high enough quality advertise. For $c \geq c_{1 \bar{q}}$, however, no quality is large enough to make advertising profitable, so that there is no advertising and no product is sold (hence there is full pooling again). For $c<c_{1 \underline{q}}$, only the pooling equilibrium with no advertising may arise. For intermediate visit costs, $c_{1 \underline{q}} \leq c \leq \tilde{c}$, the two equilibria arise.

As we show below, as more dimensions are added to the advertising mix, the structure of the set of equilibria is quite similar to that of Proposition 2. Obviously, the arguments supporting the fully pooling equilibrium with no advertising are not altered. It therefore still exists if and only if $c \leq \tilde{c}$, Furthermore, the only other equilibrium is separating and exists if and only if $c>c_{1 q}$. It is such that quality is revealed by the firm if its quality is large enough to allow its sales to be strictly positive. The additional ingredients in ads expand the range of qualities at which the firm is active. However, these additional dimensions of advertising also induce an increased complexity in the game that require much more elaborate arguments to establish that there are no other equilibria. We therefore postpone this issue to Section 7 and start by constructing the separating equilibrium in the two relevant cases of price and quality advertising and fully informative advertising, including price, match, and quality. 


\section{Quality and Price Advertising}

We now introduce price advertising as well, so that the firm may advertise both price and quality. This ability will save the lower quality firm types from extinction. Low-quality types will advertise price and quality, whereas high-quality types need advertise only quality. In what follows (in this and the next section), we start with pre-supposing that the consumer does actually know the quality, and we then derive what the rest of the information disclosure strategy looks like. We then argue that indeed quality disclosure does form part of an equilibrium strategy.

If the consumer does not (yet) know her match value, she bases her sampling decision on the price and quality she sees advertised. Seeing an advertised quality, $q$, she visits if and only if the price is below some threshold value $\hat{p}(q)$, where $\hat{p}(q)$ equates the consumer's expected surplus to the search cost, that is

$$
\int_{\max \{0, \hat{p}-q,\}}^{b}(q+\varepsilon-\hat{p}) f(\varepsilon) d \varepsilon=c .
$$

The lower bound of the integral incorporates the fact that the consumer only buys when she finds her surplus is non-negative, i.e., when she finds that $\varepsilon>\hat{p}-q$. If indeed $q-\hat{p}<0$ there are some realizations of $\varepsilon$ for which she does not buy, and she factors this into her visit surplus.

Comparing this expression with (2) shows that $\hat{p}(q)$ exceeds $p^{m}(q)$ when $c<c_{1 q}$, so that the firm's best strategy would be to advertise the monopoly price, $p^{m}(q)$ (rather than a higher one that would leave the consumer with zero expected surplus). Hence, in this case, the firm has nothing to gain through reassuring price advertising since the consumer searches anyway while rationally anticipating the monopoly price $p^{m}(q)$. Thus the firm does just as well without price advertising.

For higher search costs, $c>c_{1 q}, \hat{p}(q)$ is clearly less than $p^{m}(q)$. Without price advertising, the consumer would not visit because of the hold-up problem by which the firm would charge $p^{m}(q)$ if she did. Then, in order to sell, the firm must commit to a price of at most $\hat{p}(q)$ by advertising its price. Since profit increases in price for $p$ below $p^{m}(q)$, the consumer rationally expects the advertised price to be chosen (since a firm is allowed to choose a lower price than that advertised, though not a higher one). The consumer then visits, but only buys when she finds $q+\varepsilon \geq \hat{p}(q)$. Here price advertising enables a market to exist because it credibly caps the firm's price. Note from (3) that the price $\hat{p}(q)$ is decreasing in the search cost $c$ : a lower price is required to induce the consumer to visit when search costs are higher. For any $q$, the greatest possible search cost for which price-and-quality advertising is feasible corresponds to a zero price for $\hat{p}(q)$. Inserting this bound in (3) gives the critical search cost value, $c_{p q}=\int_{0}^{b}(q+\varepsilon) f(\varepsilon) d \varepsilon$, in the following proposition. Clearly, $c_{p q}$ is increasing in $q$, and linearly increasing for $q>0 .{ }^{19}$

\footnotetext{
${ }^{19}$ Price advertising is qualitatively different according to whether $q \gtrless \tilde{q}$. If $q>\tilde{q}$, we know that the consumer
} 
It remains to be shown that all quality levels satisfying $c_{p q}>c$ are revealed for $c_{1 \underline{q}}<c$. If quality is in this range and the firm deviates to no advertising, then Bayesian updating prescribes that consumers assign probability 1 to quality such that $c_{p q} \leq c$. Sales are then zero and such a deviation is unprofitable. Any other deviations may be ruled out by appropriately formulating off-equilibrium path beliefs. The simplest way to do this is to say that beliefs put probability one on the worst type for any deviation..$^{20}$

Proposition 3 If the firm can only advertise its price and quality, there exists a separating equilibrium if and only if $c_{1 \underline{q}}<c \leq c_{p \bar{q}}$. If quality is such that $c_{1 \underline{q}}<c \leq c_{1 q}$, the firm advertises only quality, and the consumer then visits rationally anticipating the monopoly price $p^{m}(q)$. If quality is such that $c_{1 q}<c<c_{p q}$, the firm advertises price along with its quality. It chooses the price $\hat{p}(q)$ given by (3), which is strictly below the monopoly price, $p^{m}(q)$, and is decreasing in $c$.

The top half of Figure 1 illustrates the revelation strategy as a function of the quality, $q$, for given $c$ bigger than $\tilde{c}$. Specifically, the lowest quality firm types cannot get any sales regardless, a middle quality range of types advertise price along with their quality, and the top quality range need only advertise their quality. We now add the possibility of advertising horizontal match too, and show how this expands the range of viable qualities (as per the bottom half of Figure 1.)

\section{Persuasion with match revelation}

We now add a further (horizontal) match dimension to the search version of the persuasion game, in addition to the price dimension just studied. For search costs above $c_{1 \underline{q}}$, the firm's strategy in a separating equilibrium where quality is revealed is now addressed. The trade-off between including match advertising and not is as follows. Advertising price-and-quality entices the consumer to visit, but she only buys if her match value exceeds $\hat{p}-q$. When match information is added, the consumer only enters when her match value is high enough, but then she wants to buy for sure. So

buys for any realization of $\varepsilon$ at the monopoly price. Since price advertising reduces the price below the monopoly price, the consumer will always buy under price-and-quality advertising. For $q<\tilde{q}$, the consumer does not always buy at the monopoly price. Price advertising below the monopoly price will cause her to buy for more realizations of $\varepsilon$. The lowest possible price for which price-and-quality advertising might be used is zero: the consumer buys with probability one in this case (i.e., when $c=c_{p q}$ ) if and only if $q \geq 0$.

${ }^{20}$ One might object to this belief if the purported price set is clearly inconsistent with the lowest-firm's profitability. For example, the price could be way above its profit-maximizing price, $p^{m}(\underline{q})$. One might then impose the consistency condition that the price be consistent (should the consumer visit) with a price that would give the firm at least as much profit as if it specified its true quality and the corresponding price $\hat{p}(q)$. We now show that there are beliefs that satisfy this consistency condition and would deter a firm from announcing only a price. Suppose the first announced a price $p^{\prime}$ which is such that there is a $q^{\prime}$ for which $p^{\prime}=\hat{p}\left(q^{\prime}\right)$. Then we may specify beliefs that put probability 1 on $q=q^{\prime}-\delta$ (with $\delta>0$ and small). But then consumers observing $p^{\prime}$ would not visit, so disclosing $p^{\prime}$ alone would not be a profitable deviation. 
the first case tends to emphasize market share over margin, while the second emphasizes margin over market share.

We consider match information that tells the consumer her exact match value (her $\varepsilon$ ) if the firm chooses to advertise this horizontal information. ${ }^{21}$ The consumer then decides whether the seller offers enough surplus to warrant visiting and buying. For $c$ just larger than $c_{1 q}=S^{m}(q)$, we know that advertising only quality is just infeasible (because the consumer will not incur the search cost). ${ }^{22}$ However, we know that the full monopoly profit was attainable for slightly lower $c$. Hence, by continuity, if the firm advertises a price slightly below the monopoly price, it will induce the consumer to buy as long as $c$ is sufficiently close to $S^{m}(q)$, and this will enable the firm to make a profit arbitrarily close to the monopoly profit. However, if price and full match are revealed along with quality (which we shall call "full" advertising, for short), the profit is strictly below the monopoly level. This is because the willingness to pay under full match advertising is lower by $c$ than the demand price conditional on visiting. Hence the highest profit attainable under this demand must be strictly below the monopoly level.

The argument above establishes that price-and-quality advertising must dominate full advertising in a neighborhood of $c$ values just exceeding $c_{1 q}$. However, for $c$ too large $\left(c>c_{p q}\right)$, priceand-quality advertising results in a zero price (given all consumers are to be induced to visit, and averaging across all possible outcomes for $\varepsilon$ ), whereas price-and-match advertising still leads to positive profit at such a value of $c$. Anderson and Renault (2006) show that, for given $q$, the profit function for price-and-quality advertising is concave in $c$ while it is convex in $c$ under full advertising. This means there is a unique critical $c$, call it $c_{f q}$, for which price-and-quality advertising dominates for $c<c_{f q}$ and full advertising dominates for $c>c_{f q}$.

We now show that the critical switch point between the two advertising types, $c_{f q}$, is increasing in $q$. This means that price-and-quality advertising will be used up to larger values of $c$ for higher qualities.

Under price-and-quality advertising, the price is given by the threshold value $\hat{p}(q)$ which equates the consumer's expected surplus to the search cost, as per (3) above. The corresponding profit is

$$
\hat{\pi}=\hat{p}(q)[1-F(\hat{p}(q)-q)]
$$

and this applies whether or not the consumer always buys ex-post (if she does, then simply $F(\hat{p}(q)-q)=0)$.

The derivative of this profit with respect to $q$ is (using (3) to show that $\frac{d \hat{p}(q)}{d q}=1$ : note that

\footnotetext{
${ }^{21}$ For example, the firm could advertise its position on a Salop (1979) circle.

${ }^{22}$ This argument rephrases that in Anderson and Renault (2006).
} 
the envelope theorem does not apply because the visit constraint is binding):

$$
\frac{d \hat{\pi}}{d q}=1-F(\hat{p}(q)-q)
$$

which is just the demand under price-and-quality advertising. Intuitively, a quality increase enables an equal price increase, leaving the demand base the same (that is, the pass-on rate for quality is 1.)

Under full advertising, the demand is $1-F(p+c-q)$. Letting $p^{f}(q)$ be the optimal price and applying now the envelope theorem to the profit function gives the profit derivative as $\frac{d \pi^{f}}{d q}=$ $p^{f}(q) f\left(p^{f}(q)+c-q\right)$, or, using the pricing first-order condition:

$$
\frac{d \pi^{f}}{d q}=1-F\left(p^{f}(q)+c-q\right)
$$

Once again, this expression also applies when the consumer always buys. However, it is readily shown that the price-and-quality strategy is preferred if the consumer always would buy at the optimal full advertising price. This is because a price $p=q-c$ that brings in the lowest consumer valuation (namely, $\varepsilon=0$ ) under full advertising would necessarily bring in the consumer (who would always buy) under price-and-quality advertising. This holds for slightly higher prices too, since the surplus provides a buffer.

Evaluating the derivative expressions (4) and (5) at a point where the profits are equal (the switch-over point, $c_{f q}$ ) indicates that the profit derivative for full advertising is lower because demand is lower (the profit equality from the two strategies at such a point comes from the lowprice/high volume price-and-quality strategy equalling the high-price/low volume price and match strategy). ${ }^{23}$ Hence, starting from any (quality-cost) point where profits are equal, price-and-quality dominates for higher qualities. However, as noted above, starting from any (quality-cost) point where profits are equal, full advertising dominates for higher costs. The derivative properties above imply that $c_{f q}$ is an increasing function of $q$, as shown in Figure 2.

Finally, the largest value of $c$ at which anyone will buy for full advertising (at a price of zero) is where $c=b+q$, which is clearly increasing (linearly) in $q$. This is the right-most locus in Figure 2 , which pulls together the above results for price-and-quality and full advertising (see also the bottom half of Figure 1 which gives the quality snapshot for a given $\left.c \in\left(\tilde{c}, c_{1 \tilde{q}}\right)\right)$.

In summary:

\footnotetext{
${ }^{23}$ Recall that the price $\hat{p}(q)$ is below the monopoly price $p^{m}(q)$ (and is decreasing in $c$ ) for $c>c_{1 q}$ with equality (and continuity) at $c=c_{1 q}$. However, under full advertising, the "full" price faced by consumers, $p^{f}(q)+c$, is increasing in $c$. This latter property follows from the strict log-concavity of demand, $1-F\left(p^{f}(q)+c-q\right)$, and it means that the full price is above the monopoly price (which attains under full advertising at $c=0$ ). This in turn means that the quantity demanded under the price-and-quality strategy must be higher.
} 
Proposition 4 If the firm can advertise its match, price, and quality, there exists a separating equilibrium if and only if $c_{1 \underline{q}}<c<b+\bar{q}$. If quality is such that $c_{1 \underline{q}}<c \leq c_{1 q}$, the firm advertises only its quality, and the consumer then visits rationally anticipating the monopoly price $p^{m}(q)$. If quality is such that $c_{1 q}<c \leq c_{f q}$, the firm advertises price along with its quality. It chooses the price $\hat{p}(q)$ given by (3), which is strictly below the monopoly price, $p^{m}(q)$, and is decreasing in c. If quality is such that $c_{f q}<c \leq b+q$, the firm also advertises its full match, and its price $p^{f}$ decreases with $q$ while the full price $p^{f}+c$ increases with $q$.

On the vertical axis of Figure 2 we indicate quality, starting out with the lowest possible one, $\underline{q}=-b .{ }^{24}$ Search cost, $c$, is on the horizontal axis. Notice that we could think of a given industry as being characterized by a particular level of $c$ and a range (and distribution) of qualities. We therefore describe the separating equilibrium disclosure strategies indicated in the Figure in terms of firm quality for given $c$. For $c \in\left(0, c_{1} \tilde{q}\right)$, a high quality firm need only advertise its quality to induce visits by all consumers. For medium qualities (such that $c \in\left(c_{1 q}, c_{f q}\right)$ ), the firm advertises price (as reassurance) along with quality because consumers would not visit if they expected monopoly pricing. For low quality (such that $c \in\left(b+q, c_{1 q}\right)$ ), a firm prefers to also advertise its match because doing so allows it to charge a higher price by screening out some of the lower value consumers. A very low quality firm $(q<c-b)$ cannot survive - even revealing its horizontal match and pricing at cost could not get even the highest valuation consumer $(\varepsilon=b)$ to visit and buy. For large $c>c_{1 \tilde{q}}$ no firm can survive by advertising quality only. This is because for $q>\tilde{q}$ then $c_{1 q}=c_{1 \tilde{q}}$ (see Proposition 2). Otherwise, the pattern is the same as described above.

\section{Uniqueness of equilibrium}

The separating equilibrium that is characterized in Proposition 4 has the property that quality is always advertised. We now show that this property must hold in any equilibrium. It is then immediate that the only equilibria in the game are the pooling equilibrium of Proposition 1 and the separating equilibrium of Proposition 4. The following result is proved in the Appendix.

Proposition 5 In any equilibrium, the firm never advertises without advertising quality.

Having just established that quality is revealed, the analysis leading to Proposition 4 shows that the unique equilibrium behavior for the firm is that described in the Proposition. We now show that there is no equilibrium where some (but not all) firm types advertise (among those that make strictly positive sales). Indeed, this would require that, upon seeing no ad, the consumer chooses

\footnotetext{
${ }^{24}$ Figure 2 assumes there is a quality $\underline{q}=-b$ in the marketplace (with associated search $\operatorname{cost} c_{1 \underline{q}}=0$ ).
} 
to visit. But then the firm could earn its monopoly profit while not advertising, no matter what its quality. From our tie-breaking rule, there would then be no advertising; a contradiction. Hence, in equilibrium, either there is no advertising by any type or else the firm uses advertising whenever it is active. This leads to the following result.

Corollary. For $c \leq c_{1 \underline{q}}$ the unique equilibrium is the pooling equilibrium of Proposition 1. For $c>\tilde{c}$ the unique equilibrium is the separating equilibrium of Proposition 4 . For $c_{1 q}<c \leq \tilde{c}$, both equilibria exist.

\section{Implications}

We present below some suggestive results from newspaper advertisements for airlines. Advertising does not seem to constitute a large fraction of the sales price for airlines, but is relatively informative in content, without a lot of "persuasive" (uninformative) advertising, and so is broadly consonant with our set-up. We proceed as if our monopoly analysis also applies to competition. One caveat here is that the presence of competitors might reasonably increase the amount of price advertising (beyond the degree predicted in the monopoly model) as airlines try to entice customers from their rivals. Another caveat is that the model in the text does not allow for partial information disclosure, although we do observe firms that mention only some characteristics and not others.

One difficulty with empirical validation is in distinguishing horizontal from vertical information. Horizontal information might involve many different categories of the service, and so many different aspects of service might have to be described. It does not follow that observing many different types of information indicates that horizontal match information is being revealed: indeed, such an observation may represent vertical information.

The theory considers effectively a single ad type, but we observe multiple ads with different characteristics in each. One interpretation is that the observed ads profile conveys the average message profile the airline wants to convey (and individual ads are constrained by the consumer's difficulty in absorbing several messages in the same ad). Our major focus was on the fraction of ads involving prices. We might also think of each airline as having a number of routes as its products: then the ones with higher search costs or lower quality ones (or, intuitively, those with more competition) might be more likely to be price advertised. In that way we might think of airlines with low quality across the board as likely to find themselves wanting to use price advertising for more of their products (i.e., price advertising becomes more likely). ${ }^{25}$

\footnotetext{
${ }^{25}$ The theory supposes that price information is all-or-nothing. In practice, there is frequently partial price information insofar as only some precise prices are advertised (on given routes in the airline context). The argument in the text suggests that more price information would be advertised by those airlines with lower qualities. In the data we do not strictly observe price-only ads because ads need to specify the destination they are talking about (the firms
} 
We collected (and photocopied into a file) all the ads for US carriers that appeared in the WP, NYT, WSJ for 2004 and 2005 (plus an extra 6 months of NYT for 2003). We recorded the pagesize of the ad, the carrier, and various categories of information (raw information cues) described further below. ${ }^{26}$ Restricting attention to those airlines with over 15 full pages of ads, there are 5 large airlines, American Airline (AA), Continental (CO), United Airline (UA), Us Airline (US), Delta Airline (DL). There are two intermediate size airlines, Jet Blue (B6) and Independence Airline (DH), and 2 small airlines, ATA (TZ) and USA 3000 (U5).

First consider the disclosure of price information, which can be hard information when it involves publishing fares, or soft, when it involves general statements about low prices and price breaks. When we consider the overall percentage of advertising space devoted to (soft or hard) fare information, airlines may loosely be classified into three categories. A first group of airlines devote a very large fraction of ad space to fare information and comprises USA 3000 (99.66\% of ad space devoted to fares) and ATA (78\% of ad space devoted to fares). For a second category of airlines, the fraction of ad space devoted to fares is intermediate: American (43\%), Jet Blue (39\%), Independent (41\%), United (56\%) and US Air (44\%). Finally, Continental and Delta devote only a very limited amount of ad space to fares ( $6 \%$ and $24 \%$ respectively).

Note that the two smallest airlines make the most extensive use of price advertising, which somewhat corroborates the theory if size reflects quality. They are also the two airlines that devote the largest fraction of their ad space to published fares (91\% for USA 3000 and $26 \%$ for ATA while this percentage is at most $18 \%$ for other airlines). It is also consistent with our theoretical predictions that the two airlines that advertise prices the least are large. They are also the two airlines that devote the least space to published fares ( $2 \%$ for Continental and $4 \%$ for Delta). However, one caveat here is that it may be easier to advertise price for small airlines insofar as they have few routes.

The intermediate group with regard to price advertising is a mix of two low-cost airlines and three large legacy airlines. Although the latter three airlines might have been expected to do less price advertising according to our theoretical analysis, a few observations somewhat mitigate this negative conclusion. First, a likely explanation for United being the third in terms of advertising space devoted to fare is that these ads include those for Ted, a low-cost airline that was started

we observe are multi-product ones in the sense that they have multiple routes, and these routes have different prices).

${ }^{26}$ We eliminated from the data-set ads for airline credit cards since these seemed primarily for the card rather than the airline. We also ignored ads for package holidays involving an airline's partner. Note that we considered a short time period, over which special events occurred: the entry of Independence Air for 18 months, and its corresponding introductory ads, which provoked both UA's ads and its introducing the splinter Ted. Note too that the WP is UA territory - it has much larger presence in DC; while CO was a major player in NY, although WSJ (and to a lesser extent NYT) has larger circulation footprint than just the immediate NY area. 
by United during that period in reaction to the competition from Independent. Second, US Air obviously has an advertising profile that is inconsistent with its status as a major airline. It is the airline with the third percentage of space devoted to published fares (18\%). Such atypical behavior might be attributed to the commercial difficulties of US Air over that period that led to into Chapter 11. Finally, although American devoted a fairly large advertising space to general fare claims, it only devoted $8 \%$ to published fares (the third lowest percentage).

Rather loosely, there were three main types of firm, and these can be related to the typology of Figure 2 for the cost range $c \in\left(0, c_{1 \tilde{q}}\right)$, with $\underline{q}$ above the quality level associated to $c_{f q}$. That is, think of the industry as being described by a given $c$, with a range of qualities in the marketplace, so think of a vertical segment in the interior of Figure 2. The lowest quality firms, if at the lowest possible quality (which we might think of as being enforced by the FAA) have no need to advertise quality, but for the supposed cost level they do need to advertise price to get the consumer to look at them. The high quality firms need no price advertising (if they are above the quality defined by $c_{1 q}$ ). The middle group of firms needs to advertise whatever qualities it has (so they distinguish themselves from the lowest possible qualities), and they need to advertise prices too as reassurance to the consumer that they are not too expensive.

\section{Conclusions}

Our analysis provides a broader footing to the "Persuasion Game" (whereby the firm chooses how much quality information to reveal) previously analyzed by Milgrom (1981) and Grossman (1981) and several subsequent authors, and situates it squarely as a model of advertising. In our model, advertising entices consumers to find out more about the good and allows for price and horizontal information disclosure along with quality. The analysis further enriches the empirical predictions of the model.

We have shown that quality is fully disclosed if search costs are not too small. It is the first dimension that is advertised by the firm as the search costs increases, and low quality firms provide more information than high quality ones. Price and horizontal match information follow for higher search costs.

Low-quality sellers need to advertise price along with some horizontal information in order to convince that small set of buyers interested in its service to buy. Indeed, a low-quality firm may advertise quality (which, if very low, would not need to be advertised), price, and horizontal differentiation information, while a high quality counterpart may only advertise quality (Swiss watches also come to mind). This is the type of pattern indicated in Figure 2. The lowest quality firms as providing the most specific match info which will appeal to relatively few consumers. An 
example of the low-quality firm that fits the prediction is borne out by looking more closely at the ads of Air Tran. ${ }^{27}$ No quality information is provided, consistent with them being taken (as per the persuasion game), as the lowest possible quality. But very detailed price information is given, along with exact place of flight (JFK to Miami) and the days (Tuesday and Friday) and times of service. By contrast, Continental focuses on broad indicators of quality, with very little price information, corresponding to the actions of a high-quality seller in such a low search-cost regime.

We have made various special assumptions in this analysis, and further research ought to extend the basics here. One direction concerns looking at restrictions on the type of horizontal match information that may be imparted through an ad. We took an extreme case in which the firm could impart only full match information. In the appendix we describe the separating equilibrium when the firm may disclose any consistent partial match information. We draw on results in Anderson and Renault (2006) which show that the optimal match strategy (when deployed) is to communicate simply a threshold match such that the consumer infers from the ad that her match is either above or below the threshold. We show that a separating equilibrium exists for the same range of visit costs as the separating equilibrium with full match information in Proposition 4. Allowing for partial match information shifts the price-match mix in favor of more match and less price advertising. High quality firms still provide less information.

We have introduced quality in a specific additive manner: analyzing the case of consumers with different willingness to pay for quality would be more in line with traditional models of vertical product differentiation. Likewise, search cost heterogeneity (see Rob, 1985, Stahl, 1989 and 1996, Konishi and Sandfort, 2002, and the discussion in Anderson and Renault, 2006) is an important feature of markets. We would not expect the "quality-first" proposition to change if we introduced heterogeneity in quality valuation or search costs, although this remains to be verified. Introducing a cost of advertising would likely change the nature of the separating equilibrium. We would expect a semi-separating equilibrium to arise, at which high quality firm types separate by revealing quality, while low-quality types pool on remaining mum (the indifferent firm type would be such that the advertising cost would equal its profit increment over the profit from being taken as the average quality over the set of types pooling).

Another direction for consideration, along the lines of the original persuasion game, is to treat the good as an experience one in the quality dimension. It is then quite straightforward to establish there will be quality unravelling in the case of zero visit costs: the argument generalizes for positive visit costs, although there are more cases to consider.

Our monopoly analysis might be usefully extended to oligopoly, and the "reach" decision of how

\footnotetext{
${ }^{27}$ Air Tran was excluded from the analysis of the previous section through lack of volume in ads.
} 
many consumers to inform would bring the current work closer to existing work on advertising that has looked only at the reach decision but not the content decision. Together with the extension to oligopoly, such extensions would provide a much more complete picture of the forces at play in the market for advertising.

\section{Appendix 1: Proof of Proposition 5}

We proceed in three steps. First we show that if for some quality the firm advertises some information other than quality, then it always advertises its price. Second, we show that there cannot be a set with positive measure of qualities that pool in the second stage in equilibrium (by disclosing the same information). Finally we show that there cannot be a fully separating equilibrium if there is a set with positive measure of qualities that do not reveal quality.

Step 1 We proceed by contradiction. Consider an equilibrium such that a non-empty set of qualities $Q$ all advertise full match information but neither quality nor price. Let $p^{*}(q)$ be the equilibrium price charged by a firm with quality $q \in Q$, in equilibrium. Consider a firm with quality $q_{0} \in Q$ such that $q_{0}-p^{*}\left(q_{0}\right)>\sup _{q \in Q}\left\{q-p^{*}(q)\right\}-c$. Consider a consumer who visits. Then her match $\epsilon$ must be at least $-\sup _{q \in Q}\left\{q-p^{*}(q)\right\}+c$, otherwise she could not obtain a positive surplus from visiting and buying a product in $Q$. The consumer's surplus from buying quality $q_{0}$ at price $p^{*}\left(q_{0}\right)$ is $\epsilon+q_{0}-p^{*}\left(q_{0}\right)>0$. Hence, the firm with quality $q_{0}$ could increase its price slightly without losing any customer. This contradicts $p^{*}\left(q_{0}\right)$ being the equilibrium price for quality $q_{0}$.

Step 2 We again proceed by contradiction. Consider a candidate equilibrium where some nonzero measure, $Q$, of qualities pool by disclosing the same information without quality. First note that if a quality $q \in Q$ is such that $S^{m}(q) \geq c$, then all firm types in $Q$ must pool on charging the price $p^{m}(q)$. Otherwise, the firm with quality $q$ could deviate by revealing its quality and charge $p^{m}(q)$, thus earning its monopoly profit. This in turn implies that $Q$ cannot contain more than one quality $q$ satisfying $S^{m}(q) \geq c$. Now, define $q_{\text {sup }}=\sup Q$. First suppose that $S^{m}\left(q_{\text {sup }}\right) \geq c$. Then, because we have just established that there is at most one quality in $Q$ satisfying $S^{m}(q) \geq c$, either it is $q_{\text {sup }}$ or there is no such quality. In either case, since $q$ is continuously distributed, then $S^{m}(q)<c$ with probability 1 for $q \in Q$.

Case $1 q_{\text {sup }} \in Q$ and $S^{m}\left(q_{\text {sup }}\right) \geq c$. First assume that firms with quality in $Q$ advertise no match information and only a price, which should be $p^{m}\left(q_{\text {sup }}\right)$ as was argued above. Since $p^{m}(q)<p^{m}\left(q_{\text {sup }}\right)$ with probability 1 for $q \in Q$, the expected surplus of a consumer who finds quality $q$ after visiting is strictly less than $S^{m}(q)$ with probability 1 . Hence, the ex ante expected surplus of the consumer before she visits is strictly less than $S^{m}\left(\sup \left\{q \in Q \mid S^{m}(q)<c\right\}\right) \leq c$. Hence the consumer will not visit and the firm will earn zero profit. But the firm with quality $q_{\text {sup }}$ 
could then deviate by revealing its quality and earn its monopoly profit.

Now assume that firm types with quality in $Q$ advertise match as well as price. This is clearly suboptimal for a firm with quality $q_{\text {sup }}$, which would again be better off disclosing its quality, but not advertising the match. This is because if match is advertised, it sells only with probability $1-F\left(p^{m}\left(q_{\text {sup }}-q_{\text {sup }}+c\right)\right.$, whereas it sells with probability $1-F\left(p^{m}\left(q_{\text {sup }}\right)-q_{\text {sup }}\right)$ if it advertises quality only, so that the consumer visits with probability 1.

Case $2 q_{\text {sup }} \notin Q$ or $S^{m}\left(q_{\text {sup }}\right)<c$

Again we start by assuming that firms with quality in $Q$ advertise price only. Consider a firm with quality $q$ arbitrarily close to $q_{\text {sup }}$. If it reveals its quality, it can set its price so as to make the consumer indifferent between visiting or not. If it pools with other qualities in $Q$, the price must be lower in order for the consumer to be willing to visit, since she expects the quality to be less than $q$ with a probability close to 1 . Since $S^{m}(q)<c$, these prices are less than $p^{m}(q)$ and a firm with quality $q$ is better off disclosing its quality and charging a larger price that yields a higher profit.

Assume now that firm types with quality in $Q$ advertise price and match. A firm with quality $q$ close to $q_{\text {sup }}$, if it reveals its quality may earn its full advertising profit. If it pools with other qualities in $Q$, for any price it charges, the probability that the consumer buys its product is lower. This is because the marginal consumer (who is just indifferent between visiting and buying the product if she knows that the quality is $q$ ) chooses not to visit if she expects quality to be less than $q$ with a probability close to 1 . Hence it cannot earn as much as what it would earn by disclosing its quality. It is therefore not an equilibrium that all qualities in $Q$ pool.

Step 3 In a separating equilibrium, the consumer knows the firm's quality, whether it is disclosed or not. Then, the firm's profit maximizing behavior is described by the equilibrium with full quality revelation characterized in Proposition 4 , for $c>c_{1 q}$. Note that the corresponding profit can always be achieved by a firm that chooses to reveal its quality so that the firm should earn that profit for all quality levels in a separating equilibrium.

Consider now a candidate separating equilibrium that replicates the firm's behavior described in Proposition 4 in terms of pricing as well as price and match revelation. Assume however that, for some non-zero measure set of qualities, the firm chooses not to disclose quality. First note that this set cannot include any quality that is so high that the firm finds it optimal to disclose no price or match information. Otherwise, types with lower qualities would have an incentive to mimic such high quality firms, to get the consumer to visit and then obtain their monopoly profits, which they cannot achieve if their true quality is revealed.

Now assume there is a positive measure of qualities that are not revealed and that are such that it is optimal for the firm to advertise price only. Because the set has positive measure, there must 
exist some quality level $q$ and some interval $[q, q+\delta)$, with $\delta>0$ such that almost all qualities in that interval are not revealed by the firm. A firm with quality $q$ prices at $\hat{p}(q)<p^{m}(q)$ and a firm with quality $q^{\prime}>q$ prices at $\hat{p}\left(q^{\prime}\right)>\hat{p}(q)$. Since $\hat{p}$ is continuous, if $q^{\prime}$ is sufficiently close to $q$, then $\hat{p}\left(q^{\prime}\right)<p^{m}(q)$. There must exist one such $q^{\prime}$ such that the firm does not advertise quality. The firm with quality $q$ can therefore mimic the firm with quality $q^{\prime}$, by advertising price $\hat{p}\left(q^{\prime}\right)$, and make more profit by the quasi-concavity of profit.

Similarly, we can show that if there is a positive measure of qualities that are not advertised and for which it is optimal for the firm to reveal price and match, then some quality level may mimic some higher quality and thus earn more profit than in the candidate equilibrium. As above, we may consider a quality $q$ and an interval $[q, q+\delta)$ where the firm does not reveal quality almost everywhere. In the candidate equilibrium, the quality $q$ firm charges $p^{f}(q)<p^{m}(q)<p^{f}(q)+c$ and the quality $q^{\prime}$ firm charges $p^{f}\left(q^{\prime}\right)>p^{f}(q)$. Standard comparative statics shows that $p^{f}\left(q^{\prime}\right)-q^{\prime}<$ $p^{f}(q)-q$. If quality $q$ mimics quality $q^{\prime}$ by announcing price $p^{f}\left(q^{\prime}\right)$ the consumer, expecting quality $q^{\prime}$, visits as long as $\epsilon \geq p^{f}\left(q^{\prime}\right)-q^{\prime}+c$ and then she buys if $\epsilon \geq p^{f}\left(q^{\prime}\right)-q$. For $q^{\prime}$ sufficiently close to $q$, the consumer buys with probability $1-F\left(p^{f}\left(q^{\prime}\right)-q+c\right)$, which is larger than the probability $1-F\left(p^{f}(q)-q+c\right)$ that the consumer buys in the candidate equilibrium. Hence the quality $q$ firm may sell with a higher probability at a higher price by mimicking quality $q^{\prime}$.

We conclude that a separating equilibrium where the firm does not reveal quality for some set of qualities with positive measure would require that at some quality level, the firm does not pick the profit maximizing behavior associated with that quality, which yields a contradiction.

\section{Appendix 2: Persuasion with partial match revelation}

Under partial match information, the firm may resort to the most general information partitions, and so can communicate any truthful information about matches (full match information is a special case of this). The firm may then choose to impart any beliefs about the match value on the consumer, as long as they are consistent with Bayes rule (implying in particular that not all consumer types can receive good news about their match). Anderson and Renault (2006) showed (for fixed qualities) that the firm would choose a threshold match strategy that communicates to the consumer whether or not her match is above or below a chosen threshold level. The intuition is (loosely) that there is no point to having visit types who will not buy, and so these should be screened out (told that their matches are below some threshold). Apart from the threshold, information should be as vague as possible (meaning that all types above the threshold get the same signal): otherwise some types would get a less favorable signal and this would tighten the visit constraint faced by the firm, which must set a low enough price so that all consumer types 
above the threshold visit. ${ }^{28}$ The optimal disclosure strategy for the firm may be characterized by defining three critical search cost values at which the firm modifies the information provided through its ads. Results applied to different quality types are as follows.

As for the full match advertising problem analyzed in the text, there exists a pooling equilibrium with no advertising as described in Proposition 1. As long as $c \leq c_{1 \underline{q}}$, consumers visit with no advertising even if they expect the worst, so that the pooling equilibrium is unique in this region. It is also still the case that the market is not viable if $c \geq b+\bar{q}$ so there are no sales and no advertising for such high visit costs. We now provide a characterization of a separating equilibrium with threshold match advertising for $c_{1 \underline{q}} \leq c \leq b+\bar{q}$. As with its counterpart in Proposition 4, it has the property that if a firm advertises at all, it always reveals its quality. Again, this property is obtained by specifying off the equilibrium path beliefs that put probability 1 on the lowest quality if no quality information is included in an ad. It is immediate that this equilibrium also has the property that as long as $c \leq c_{1 q}$, the firm does not advertise any information about price or match, and quality advertising alone is sufficient to reap the full monopoly profit.

To describe the firm's behavior for larger search costs, let us define, for any $z \in(-\infty, b)$,

$$
\phi(z)=\frac{\int_{z}^{b}(\epsilon-z) f(\epsilon) d \epsilon}{1-F(z)},
$$

which represents the expected consumer surplus, net of $z+q$, conditional on the match exceeding $z .^{29}$ For instance, if the firm charges $p$ while informing consumers willing to pay that price that they are (i.e., by disclosing a threshold of $z=p-q$ for $\epsilon$ ) then these consumers' expected surplus from buying at price $p$ is $\phi(p-q)$. A special case is when the firm charges $q$ so that all consumers are willing to pay the price: then expected consumer surplus is $\phi(0)$. This case arises for $q \geq \tilde{q}$, with no advertising (Proposition 1) or quality-only advertising (Proposition 2). Lemma 2 in Anderson and Renault (2006) shows that $\phi$ is decreasing if $f$ is log-concave. It tends to zero as $z$ tends to $b$.

For $c>c_{1 q}$, the firm may be able to still earn the full monopoly profit by judicial use of threshold information. Specifically, it gains nothing whenever the consumer does not buy after incurring the visit cost. Advertising to the consumer that her match value is low (below the monopoly price net of quality) will lose no sales but will raise the expected surplus from visiting for the consumer if she does not get such detrimental information. This broadens the footprint of the monopoly pricing regime to larger $c$ values whenever $q<\tilde{q}$ : for $q \geq \tilde{q}$, the monopoly price is $q$, so the probability

\footnotetext{
${ }^{28}$ Formally, the firm may select the joint distribution of the signal received by the consumer and the match realization, subject to the constraint that the marginal distribution of the match realization coincides with the prior F. Saak (2006) and Kamenica and Gentzkow (2011) use a similar assumption and also find that optimal disclosure involves a threshold in the case where no search is allowed.

${ }^{29}$ Another way of writing this expression is $\phi(z)=\frac{\int_{z}^{b} \epsilon f(\epsilon) d \epsilon}{1-F(z)}-z$.
} 
that the consumer is not willing to pay that price is zero.

More formally, if the firm charges $p^{m}(q)$ and discloses match information reassuring the consumer that she is willing to pay the monopoly price whenever $q+\epsilon \geq p_{m}$, then expected consumer surplus conditional on such favorable information is

$$
\frac{\int_{p^{m}(q)-q}^{b}\left[q+\epsilon-p^{m}(q)\right] f(\epsilon) d \epsilon}{1-F\left(p^{m}(q)-q\right)}=\phi\left(p^{m}(q)-q\right) .
$$

Hence a consumer with a favorable signal chooses to visit if $c \leq c_{2 q} \equiv \phi\left(p^{m}(q)-q\right)$. Notice that the firm need not advertise price at all since the consumer will rationally anticipate the monopoly price. This means that threshold match advertising alone (along with quality advertising) will ensure the monopoly profit.

For $q<\tilde{q}$ we have $c_{2 q}=\phi\left(p^{m}(q)-q\right)$. Hence, $c_{2 q}$ is strictly increasing in $q$ because $\phi$ is strictly decreasing and $p^{m}(q)-q$ is strictly decreasing in $q$. Simple inspection shows that $c_{2 q}>c_{1 q}$ for $q<\tilde{q}$ (so that $p^{m}(q)>q$ ). For $q \geq \tilde{q}$, the monopoly price is $q$ and the two expressions are the same: we have $c_{1 q}=c_{2 q}=\phi(0)$. It is also useful to show that $\tilde{q}>\phi(0)$ : this is a direct consequence of results in Anderson and Renault (2003) according to which, if demand is log-concave, monopoly producer surplus exceeds consumer surplus (the result may be applied for $q=\tilde{q}$ where the first order condition for monopoly price holds with equality).

For search costs larger than $c_{2 q}$, Anderson and Renault (2006) characterize the firm's behavior as the choice of an advertised price and threshold for $q+\epsilon$ that maximize profit subject to two constraints: the threshold should be at least as large as the price and the consumer should choose to visit when learning that her match exceeds the threshold. If the search cost is not too large, the firm charges a price $\bar{p}$ and sets the threshold at $\bar{p}-q$. The price level is just low enough that a consumer with a favorable signal visits. So it satisfies

$$
c=\frac{\int_{\bar{p}-q}^{b}[q+\epsilon-\bar{p}] f(\epsilon) d \epsilon}{1-F(\bar{p}-q)}=\phi(\bar{p}-q) .
$$

This regime lasts as long as $\bar{p} \geq c$. Since $\phi$ is strictly decreasing, then $\bar{p}$ is strictly decreasing in $c$, so there is a unique critical value of search cost $c_{3 q}$ at which $\bar{p}=c$. Hence, from $(8), c_{3 q}=\phi\left(c_{3 q}-q\right)$. For a search cost above $c_{3 q}$, the firm picks a threshold equal to $c$, to stop the consumer buying when social surplus is negative. Again, the price is at a level that makes a consumer just indifferent between visiting and not visiting if she learns her match exceeds the threshold. The price level is $\tilde{p}$ defined by $\tilde{p}=\phi(c-q)$. When $c$ rises beyond $q+b$, the firm can no longer sell, as with full match advertising.

The above solution has different implications depending on whether quality is high or low. As long as $q<c_{3 q}$, the firm must disclose threshold information to screen out consumer types that 
are below the threshold. Then, for $c_{2 q}<c<b+q$, advertising involves quality, price, and partial match information. We now show that this happens if and only if $q<\phi(0)$. From the definition of $c_{3 q} c_{3 q}$ increases with quality because $\phi$ is strictly decreasing. Further note that $q$ and $c_{3 q}$ are equal if and only if $q=c_{3 q}=\phi(0)$, and that $q<c_{3 q}$ requires $c_{3 q}=\phi\left(c_{3 q}-q\right)<\phi(0)$ (again using the monotonicity of $\phi)$. So we need $q<\phi(0)$.

For $q \geq \phi(0)$ we have $c_{3 q} \geq \phi(0)$ and hence $q \geq c_{3 q}$. Then, for values of $c$ around $c_{3 q}$, the threshold falls below $q$. Hence the probability that the consumer match is below the threshold is zero, and there is no need to disclose any threshold information. Then there is an intermediate region of search cost values for which advertising involves only quality and price information. The corresponding range of search cost values is $[\phi(0), q]$. For $c \leq c_{3 q}$, the relevant threshold from Anderson and Renault (2006) is $\bar{p}$ defined by (8), and it falls below $q$ if $c \geq \phi(0)$. For $c>c_{3 q}$, the relevant threshold is $c$, and so no threshold advertising is needed if and only if $c \leq q$. Note that since $q \geq \max \{\bar{p}, c\}, \phi(p-q)=\phi(0)+q-p$ and $\phi(c-q)=\phi(0)+q-c$ so that $\hat{p}=\tilde{p}=\phi(0)+q-c$.

Figure 3 illustrates the partition of the parameter space according to the strategy used at the separating equilibrium. For $c \leq c_{1 q}$, the monopoly price is rationally anticipated and only quality is advertised, as we had before (see Figure 2). For $c>c_{1 q}$, the firm's equilibrium behavior differs depending on its quality. If quality is low, $q<\phi(0)$, for $c \in\left(c_{1 q}, c_{2 q}\right]$ the consumer is also told the threshold match corresponding to the monopoly price. For $c \in\left(c_{2 q}, c_{3 q}\right]$, price is added to the advertising mix, with a threshold match announced equal to the price net of quality, which exceeds the search cost. For $c \in\left(c_{3 q}, q+b\right]$, the information mix is the same except with a (gross) threshold match that equals the search cost. For an intermediate quality, $\phi(0)<q<\tilde{q}$, the quality, threshold match, and price, region is interrupted by a region where only quality and price are advertised. For $\phi(0) \leq c \leq q$, both the price charged and the search cost are below $q$, so that it is not necessary to screen out consumers with threshold match information. For $c>q$, the gross threshold that is advertised is $c$ again. Finally, if quality is at least $\tilde{q}$ so that $c_{1 q}=c_{2 q}=\phi(0)$, the firm moves from quality-only to quality and price when $c$ rises above $\phi(0)$, and it introduces threshold match information for $c>q$.

To summarize, the following proposition describes this separating equilibrium.

Proposition 6 If the firm can advertise a threshold match, price and quality, there exists a separating equilibrium if and only if $c_{1 \underline{q}}<c \leq b+\bar{q}$. If $c_{1 \underline{q}}<c \leq c_{1 q}$, the firm advertises only quality, and the consumer then visits rationally anticipating the monopoly price $p^{m}(q)$. If $c_{1 q}<c \leq c_{2 q}$, the firm advertises quality and partial match information with a threshold $p^{m}(q)-q$, and the consumer with a match above the threshold visits, rationally anticipating the monopoly price $p^{m}(q)$. If $c_{2 q}<c \leq \min \left\{c_{3 q}, \phi(0)\right\}$, the firm advertises quality, price $\bar{p}>c$, and partial match information 
with a threshold $\bar{p}-q$, where $\bar{p}$ decreases in $c$. If $c \in\left(\max \left\{c_{3 q}, q\right\}, q+b\right]$ the firm advertises quality, price equal to $\phi(c-q)$, and threshold match $c-q$. If $c \in(\phi(0), q]$, the firm advertises quality and a price $\bar{p}=\tilde{p}=\phi(0)+q-c$, and the consumer always buys after visiting.

Analogous arguments to those of the Corollary in the main text for full-match advertising prove that for $c \leq c_{1 \underline{q}}$ the unique equilibrium is the pooling equilibrium of Proposition 1. Likewise, for

$c>\tilde{c}$ the unique equilibrium is the separating equilibrium of Proposition 6, while for $c_{1 \underline{q}}<c \leq \tilde{c}$, both equilibria exist.

\section{References}

[1] Abernethy A.M., D.D. Butler. 1992. Advertising information: services versus products. Journal of Retailing 68(4) 398-419.

[2] Abernethy, A.M., G.R. Franke. 1996. The information content of advertising: a meta-analysis. Journal of Advertising 25(2) 1-17.

[3] Abernethy A.M., G.R. Franke. 1998. FTC regulatory activity and the information content of advertising. Journal of Public Policy and Marketing 17(2) 239-256.

[4] Amaldoss, W., C. He. 2009. Direct-to-Consumer Advertising of Prescription Drugs: A Strategic Analysis. Marketing Science 28(3) 472-487.

[5] Anand, B., R. Shachar. 2011. Advertising, the Matchmaker. RAND Journal of Economics 42(2) 205-245.

[6] Anderson, S. P., A. de Palma, and B. Kreider. 2001. Tax incidence in differentiated product oligopoly. Journal of Public Economics 81(2) 173-192.

[7] Anderson, S. P., R. Renault. 2003. Efficiency and surplus bounds in Cournot competition. Journal of Economic Theory 113(2) 253-264.

[8] Anderson, S. P., R. Renault. 2006. Advertising Content. American Economic Review 96(1) 93-113.

[9] Bagwell, K. 2007. The Economic Analysis of Advertising. Handbook of Industrial Organization, Volume 3. Eds. M. Armstrong and R. Porter, Elsevier, North Holland.

[10] Bar-Isaac, H., G. Caruana, V. Cuñat. 2010. Information Gathering and Marketing. Journal of Economics and Management Strategy 19(2) 375-401. 
[11] Board, O. 2009. Competition and Disclosure. Journal of Industrial Economics 57(1) 197-213.

[12] Butters, G. R. 1977. Equilibrium Distributions of Sales and Advertising Prices. Review of Economic Studies 44(3) 465-491.

[13] Christou, C., N. Vettas. 2008. On Informative Advertising and Product Differentiation. International Journal of Industrial Organization 26(1) 611-629.

[14] Diamond, P. A. 1971. A Model of Price Adjustment. Journal of Economic Theory 3(2) 156-168.

[15] Dranove, D., G. Z. Jin. 2010. Quality Disclosure and Certification: Theory and Practice. Journal of Economic Literature 48(4) 935-63.

[16] Erdem, T., M. Keane, B. Sun. 2008a. A Dynamic Model of Brand Choice When Price and Advertising Signal Product Quality. Marketing Science 27(6) 1111-1125.

[17] Erdem, T., M. Keane, B. Sun. 2008b. Advertising and Consumer Price Sensitivity in Experience Goods Markets. Quantitative Marketing and Economics 6(2) 100-120.

[18] Farrell, J. 1986. Voluntary disclosure: robustness of the unraveling result and comments on its importance. In R. Grieson, ed.: Proceedings of the U. C. Santa Cruz Conference on regulation and antitrust. Lexington, MA., Heath-Lexington.

[19] Grossman, S. 1981. The informational role of warranties and private disclosure about product quality. Journal of Law and Economics 24(3) 461-483.

[20] Grossman, G., C. Shapiro. 1984. Informative Advertising and Differentiated Products. Review of Economic Studies 51(1) 63-81.

[21] Guo, L., Y. Zhao. 2009. Voluntary Quality Disclosure and Market Interaction. Marketing Science 28(3) 488-501.

[22] Iyer, G., D. Soberman, J. M. Villas-Boas. 2005. The Targeting of Advertising. Marketing Science 24(3) 461-476.

[23] Kalra, A., S. Li. 2008. Signaling Quality Through Specialization. Marketing Science 27(2) 168-184.

[24] Kamenica, E., M. Gentzkow. 2011. Bayesian Persuasion. American Economic Review 101(6) $2590-2615$. 
[25] Kihlstrom, R., M. Riordan. 1984. Advertising as a signal. Journal of Political Economy 92(3) 427-450.

[26] Koessler, F., R. Renault. 2011. When does a firm disclose product information? Mimeo, Universite de Cergy Pontoise, France.

[27] Konishi, H., M. T. Sandfort. 2002 Expanding Demand through Price Advertisement. International Journal of Industrial Organization 20(7) 965-994.

[28] Kotler, P., G. Armstrong. 2009. Principles of Marketing. (13th Ed.) Prentice Hall.

[29] Madden, C. S., M. Caballero, S. Matsukubo. 1986. Analysis of information content in US and Japanese magazine advertising. Journal of Advertising 15(3) 38-45.

[30] Matthews, S., A. Postlewaite. 1985. Quality testing and disclosure. RAND Journal of Economics 16(3) 328-340.

[31] Mehta, Nitin, Xinlei (Jack) Chen, Om Narasimhan. 2008. Informing, Transforming, and Persuading: Disentangling the Multiple Effects of Advertising on Brand Choice Decisions. Marketing Science 27(3) 334-355.

[32] Mehta, N., S. Rajiv, K. Srinivasan. 2003 Price Uncertainty and Consumer Search: A Structural Model of Consideration Set Formation. Marketing Science 22(1) 58-84.

[33] Meurer, M., D. O. Stahl. 1994. Informative Advertising and Product Match. International Journal of Industrial Organization 12(1) 1-19.

[34] Milgrom, P. 1981. Good news, bad news: representation theorems and applications. Bell Journal of Economics 12(2) 380-391.

[35] Milgrom, P. 2008. What the Seller Won't Tell You: Persuasion and Disclosure in Markets. Journal of Economic Perspectives 22(2) 115-131.

[36] Milgrom, P., J. Roberts. 1986a. Relying on the information of interested parties. RAND Journal of Economics 17(1) 18-32.

[37] Milgrom, P., J. Roberts. 1986b. Prices and Advertising Signals of Product Quality. Journal of Political Economy 94(4) 796-821.

[38] Nelson, P. 1970. Information and Consumer Behavior. Journal of Political Economy 78(2) 311-329. 
[39] Nelson, P. 1974. Advertising as information. Journal of Political Economy 82(4) 729-754.

[40] Resnik, A., B. L. Stern. 1977. An analysis of information content in television advertising. Journal of Marketing 41(1) 50-53.

[41] Rob, R. 1985. Equilibrium price distribution. Review of Economic Studies 52(3) 487-504.

[42] Saak, A. E. 2006. The Optimal Private Information in Single Unit Monopoly. Economics Letters 91(2) 276-282.

[43] Salop, S. C. 1979. Monopolistic competition with outside goods. Bell Journal of Economics 10(1) $141-156$.

[44] Shapiro, C. 1980. Advertising and Welfare: Comment. Bell Journal of Economics 11(2) 749752.

[45] Stahl, Dale O.,II (1989): Oligopolistic Pricing and Sequential Consumer Search. American Economic Review 79, 700-712.

[46] Stahl, Dale O., II (1996): Oligopolistic Pricing with Heterogeneous Consumer Search. International Journal of Industrial Organization 14, 243-268.

[47] Stern, B. L., A. Resnik. 1991. Magazine Advertising: An analysis of its information content. Journal of Advertising Research 21 39-44.

[48] Sun, M. 2010. Disclosing Multiple Product Attributes. Journal of Economics and Management Strategy 20(1) 195-224.

[49] Weyl, E. G., M. Fabinger. 2009. Pass-Through as an Economic Tool, mimeo, Harvard University.

[50] Yee, M., E. Dahan, J. R. Hauser, J. Orlin. 2007. Greedoid-Based Noncompensatory Inference. Marketing Science26(4) 532-549.

[51] Zhang, J., L. Krishnamurthi. 2004. Customizing Promotions in Online Stores. Marketing Science 23(4) 561-578.

[52] Zhao, H. 2000. Raising Awareness and Signaling Quality to Uninformed Consumers: A PriceAdvertising Model. Marketing Science 1994) 390-396. 
Figure 1:

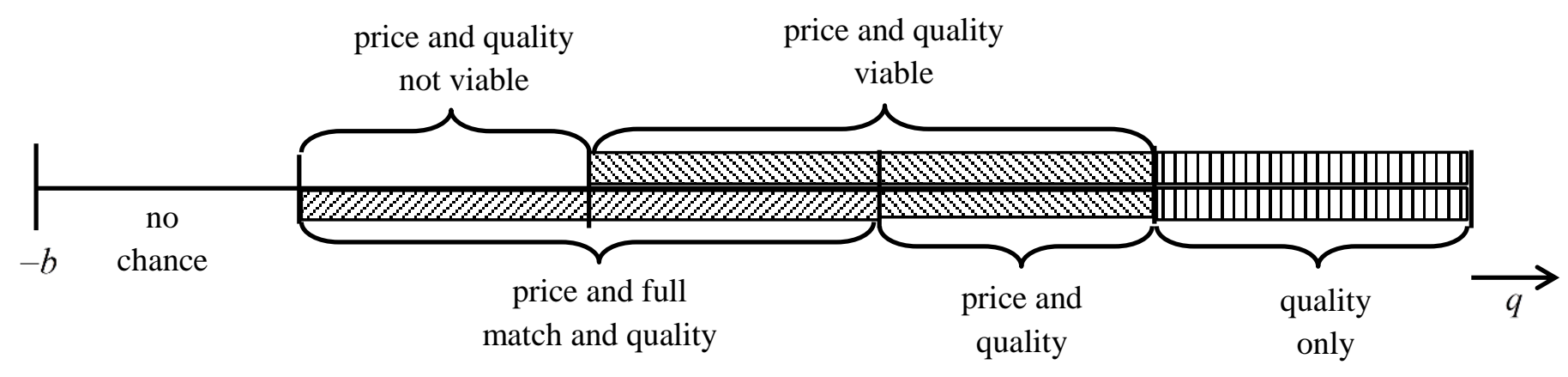




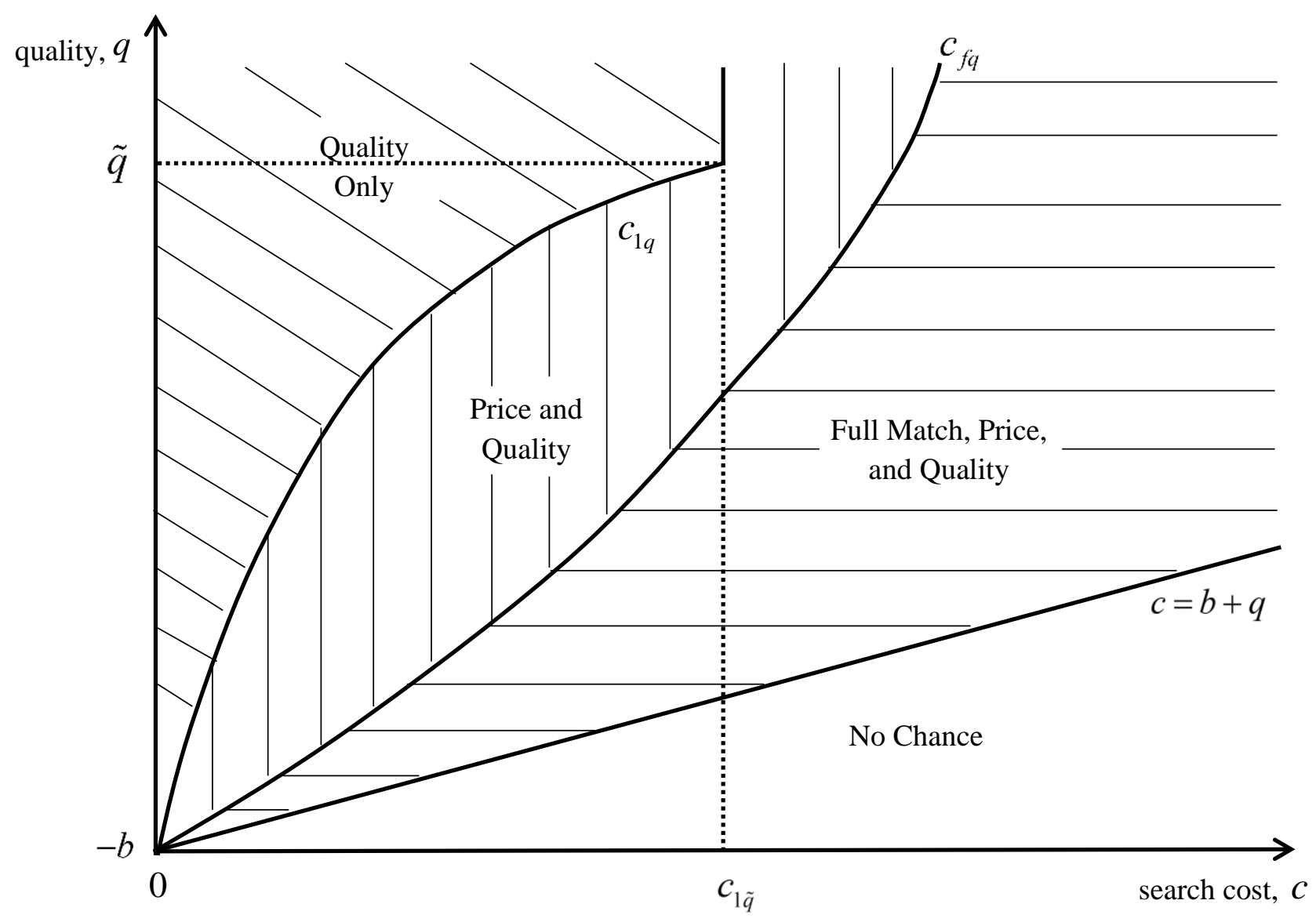

Figure 2 


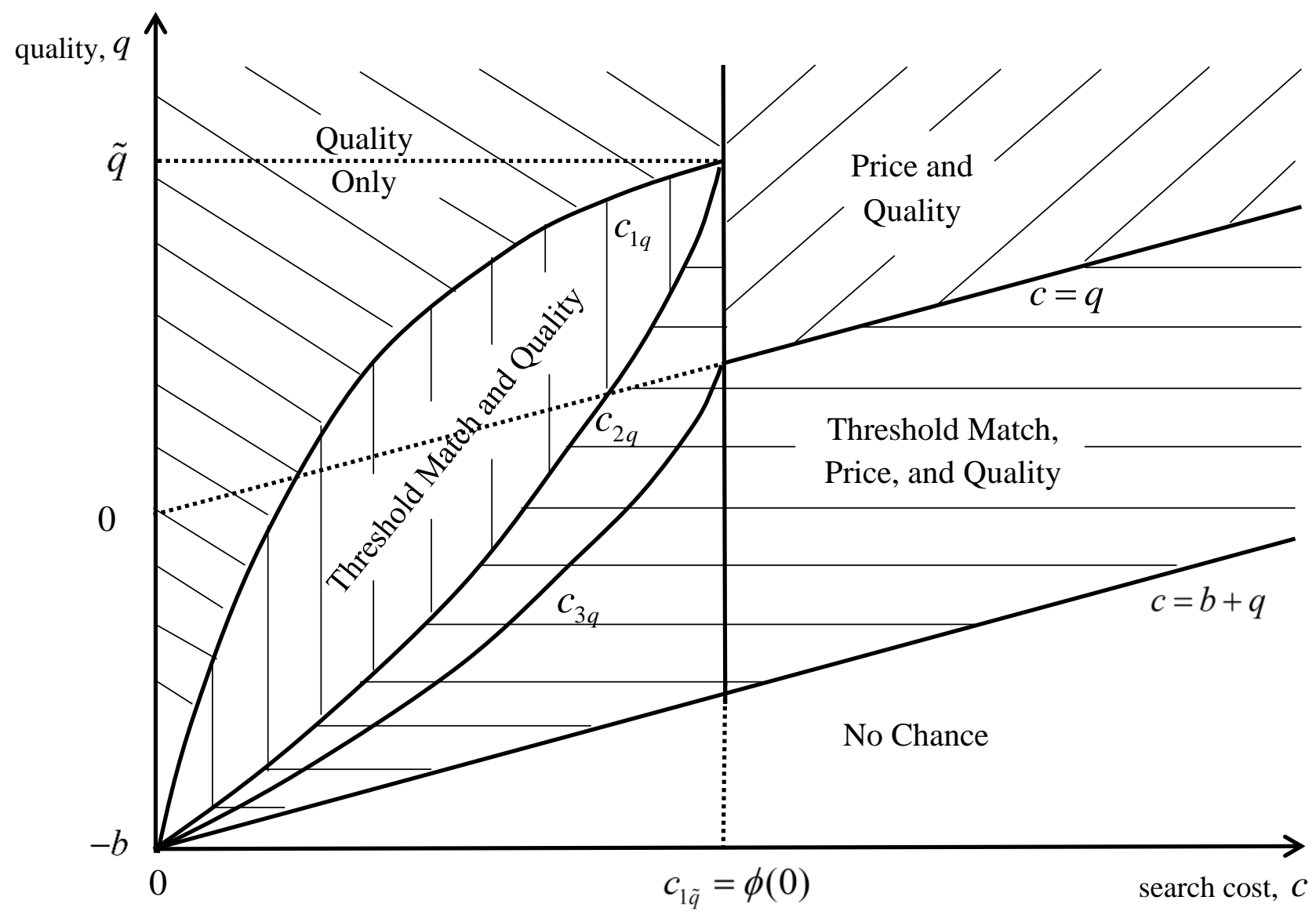

Figure 3 